\title{
FATORES PÓS - ABATE QUE CONTRIBUEM PARA A MACIEZ DA CARNE
}

\author{
Post - slaughter factors that contribute to meat tenderness \\ Caroline Posser Simeoni', Ana Paula Burin Fruet', Maria Fernanda Cáceres Menezes', Jackeline Karsten \\ Kirinus ${ }^{2}$, César Teixeira ${ }^{3}$, Luciano Antonio Ritt ${ }^{4}$. \\ 'Universidade Federal de Santa Maria (UFSM) - Aluna do Programa de Pós - graduação em Ciência e Tecnologia dos Alimentos. *E-mail de \\ correspondência: carol.posser@hotmail.com \\ ${ }^{2}$ Departamento de Medicina Veterinária, Campus Xanxerê II, Universidade do Oeste de Santa Catarina (UNOESC), Xanxerê, Santa \\ Catarina, Brasil. \\ ${ }^{3}$ Advogado e Mestre em Direito Ambiental pela Universidade de Zaragoza (Espanha). Doutorando em Direito Civil pela Universidade de \\ Zaragoza. \\ ${ }^{4}$ UFSM - Aluno do curso de Zootecnia.
}

\section{Resumo}

A cadeia de produção cárnea apresenta posição de destaque e com aumento das exigências do consumidor, pesquisas relacionadas à qualidade do produto estão sendo amplamente desenvolvidas. Dentre as características de qualidade da carne, a maciez é considerada a característica de maior influência para a satisfação do consumidor. Com finalidade de avaliar os principais fatores que influenciam na maciez da carne, realizou-se uma análise através de uma revisão de literatura sobre os procedimentos que colaboram com a maciez no post mortem, tais como maturação enzimática, PH, velocidade de resfriamento, estimulação elétrica, forma de pendurar carcaças e tenderização. Estes fatores que estão relacionados ao post mortem são considerados os mais relevantes na maciez final de produto.

Palavras - chave: Qualidade da carne, maciez, post mortem.

\begin{abstract}
The chain of meat production features prominent and increasing consumer requirements, research related to product quality are being widely developed position. Among the characteristics of meat quality, tenderness is considered the most influential characteristic for consumer satisfaction. In order to evaluate the main factors that influence respondents in meat tenderness, an analysis was performed through a literature review of the procedures that contribute to the softness in post mortem, such as enzyme maturation, $\mathrm{pH}$, cooling rate, stimulation electric, how to hang and tenderization carcasses. These factors are related to postmortem examinations are considered the most important in the final product of tenderness.
\end{abstract}

Keywords: Meat quality, tenderness, postmortem 


\section{INTRODUÇÃO}

Segundo a FAO (2012) o Brasil é o segundo maior produtor de carne bovina do mundo, depois dos Estados Unidos, e terceiro maior produtor de carne de frango, sendo Estados Unidos e a China detentores das primeiras colocações no ranking, no entanto, o Brasil é reconhecido por ser o maior exportador mundial dos produtos supracitados.

Concomitantemente ao cenário favorável do mercado cárneo brasileiro, elevam-se as exigências do consumidor e neste contexto, pesquisas relacionadas à qualidade do produto ganham espaço para aperfeiçoamento de toda a cadeia produtiva (MOMBACH et. al., 2010). Dentre as características de qualidade da carne bovina, a maciez é considerada a característica organoléptica mais importante para aquisição da carne e satisfação do consumidor (BEHRENDS et. al., 2005).

A maciez da carne é dependente das características das fibras musculares, e essa, por sua vez depende de inúmeros fatores como raça, genótipo, sexo, hormônios, desempenho de crescimento, dieta, localização do músculo, exercícios e temperatura ambiente, os quais podem alterar as características da fibra muscular e consequentemente a qualidade da carne (JOOA, 2013). Segundo Frylinck et. al. (2009) os efeitos da variação genética na maciez da carne pode ser mascarado pelas variações ambientais no post mortem como a estimulação elétrica e a temperatura de resfriamento.

Nas últimas décadas tem se tornado claro que processos metabólicos durante o post mortem têm um grande impacto na maciez da carne (GEESINK et. al., 2000; HOPKINS et. al., 2011). Com finalidade de avaliar os principais fatores que influenciam na maciez da carne, esta revisão retrata os procedimentos que colaboram com a maciez no post mortem, tais como maturação enzimática, $\mathrm{PH}$, velocidade de resfriamento, estimulação elétrica, forma de pendurar carcaças e tenderização.

\section{MATURAÇÃO ENZIMÁTICA}

Miosina e actina são as proteínas mais abundantes nas miofibrilas musculares. A interação entre essas proteínas forma a actomiosina que é responsável pela rigidez muscular. Durante o processo de rigor mortis, ocorre degradação da linha $\mathrm{Z}$, troponina, desmina, nebulina e titana, mas a actomiosina sofre pequenas mudanças no processo post mortem (HUFF-LONERGAN et. al., 2010). Sendo que os sistemas de proteases das calpaínas e catepsinas são os dois maiores sistemas proteolíticos responsáveis pela proteólise do esqueleto muscular pós abate (LAWRIE, 1998; GEESINK et. al., 2006).

Um grande número de estudos demonstra que o sistema proteolítico da calpaína desempenha papel central na proteólise post mortem e amaciamento da carne. Segundo Geesink et. al. (2006) as calpaínas são enzimas que realizam proteólise miofibrilar post mortem, são liberadas na presença de cálcio livre no sarcoplasma, apresentando maior ação nas primeiras horas do post mortem, pois agem principalmente em $\mathrm{PH}$ próximo a $6 \mathrm{e}$, após ser ativadas e causar proteólise, estas proteases perdem atividade. Hope-Jones et. al. (2010) demonstraram que o nível de $\mu$-calpaína apresenta tendência de diminuir após as primeiras horas post mortem.

O sistema de calpaínas consiste de no mínimo três proteases, $\mu$ calpaína, m-calpaína e calpaína3, além da calpastatina, que é inibidora da $\mu$ calpaína e da m-calpaína. A m-calpaína não é relacionada com a autólise do músculo no post mortem, por isso apresenta pequena importância na maciez da carne, assim como a calpaína3. Neste sentido, a $\mu$ calpaína é a principal responsável pelo amaciamento da carne no post mortem (LAWRIE, 1998; KOOHMARAIE; GEESINK, 2006).

Catepsinas também estão envolvidas com alterações da textura da carne, devido ao desarranjo da estrutura muscular que elas causam (GODIKSEN et al., 2009). Estas enzimas apresentam a característica de atuar em PH abaixo de 6 e exercer ação sobre as proteínas do tecido conjuntivo (ALVES et al., 2005)

Uma das alternativas tecnológicas mais difundidas e utilizadas pelas indústrias nacionais para melhorar e padronizar a textura é a maturação de cortes cárneos. Esse processo mantém a carne embalada a vácuo e sob-refrigeração, em torno de $0^{\circ} \mathrm{C}$, possibilitando a ação das proteases endógenas, retardando o crescimento de bactérias aeróbicas putrefativas e favorecendo o crescimento das bactérias láticas, que, por sua vez, produzem modificações bioquímicas responsáveis pela diminuição da coesão entre as miofribilas, aumentando assim a maciez. O aumento do tempo de maturação influencia diretamente o aumento da maciez e diminuição da força de cisalhamento do músculo Triceps brachii, independente da variabilidade da textura inicial (PUGA et al., 1999). Segundo Zeola et. al. (2007) carnes de cordeiro maturadas durante 14 dias apresentaram-se mais escuras, pois o valor de luminosidade foi menor em relação às carnes não maturadas e o tempo de maturação não afetou 
a capacidade de retenção de água dos músculos Bíceps femorais e Longissimus, contudo, a capacidade de retenção de água no músculo Tríceps brachii diminuiu com a maturação. Andrade et. al. (2010) revelaram que a maturação contribui com a maciez de carnes de bovinos aos sete e 21 dias por reduzir a força de cisalhamento, entretanto, interfere negativamente na coloração, portanto, a escolha do tempo de maturação adequado para carnes bovinas depende do atributo a ser valorizado.

Outros estudos demonstram que carnes não maturadas apresentaram maior capacidade de retenção de água durante sete e 14 dias (ZEOLA et. al., 2007; SILVA SOBRINHO et. al., 2005). Com relação à maciez, o tempo de maturação não influenciou a maciez do músculo Triceps brachii, porém, para os músculos Biceps femoris e Longissimus a maciez foi maior nas carnes maturadas durante sete e 14 dias, mas estas não diferiram entre si (ZEOLA et. al., 2007).

Em estudo realizado com maturação de carne de frangos, os valores de força de cisalhamento decresceram ao longo da maturação, apresentando um declínio mais acentuado nos valores de cisalhamento nas primeiras duas horas de maturação, com a maturação completa atingida em 8 horas (SANTOS et. al., 2004).

\section{VELOCIDADE DE REFRIAMENTO E PH}

Fisiologicamente, o PH muscular decresce de 7,0 logo após o abate até aproximadamente 5,4 a 5,8 , de modo que a redução de $\mathrm{PH}$ durante o resfriamento ocorre principalmente entre $6 \mathrm{e}$ 12 horas (SAVELL et al., 2005). Essa queda de $\mathrm{PH}$ é decorrente da glicólise anaeróbica que gera produção de ácido lático. Desta forma, o ácido lático e outros ácidos orgânicos promovem a queda do $\mathrm{PH}$ de aproximadamente 7 para 5,5 no espaço extracelular, o que diminui a dissociação de eletrólitos e aumenta a permeabilidade da membrana citoplasmática, facilitando a difusão de enzimas citoplasmáticas e diminuindo a coesividade da miofibrila. A ruptura de organelas citoplasmáticas, principalmente lisossomos e retículo endoplasmático, contribuem assim para o amaciamento da carne pós-abate (ASGHAR; YEATES, 1978).

$\mathrm{O} \mathrm{PH}$ muscular e a temperatura interagem continuamente durante o desenvolvimento do rigor e atuam tanto no encurtamento do sarcômero (TORNBERG, 1996) quanto na atividade das enzimas proteolíticas (DRANSFIELD, 1992).

Vários estudos demonstram que o declínio muito rápido do $\mathrm{PH}$, com uma refrigeração retardada causa um aumento da resistência da carne, devido a exaustão precoce da $\mu$ calpaína em carcaças com altas temperaturas (HWANG; THOMPSON, 2001b). A relação entre maciez da carne e $\mathrm{pH} 3$ horas post mortem tem sido demonstrada, o declínio de $\mathrm{pH}$ intermediário é identificado como ótimo para obtenção de maciez (PIKE et al., 1993).

Segundo Hwarg e Thompson (2001b), o PH e a temperatura apresentam efeitos significativos na redução da atividade da $\mu$ calpaína 4 horas post mortem, pois a calpaína é mais sensível a variação de $\mathrm{pH}$ e temperatura do que a calpastatina nas primeiras horas do post mortem. Após 24 horas, também houve interação do $\mathrm{PH}$ e da temperatura na atividade da calpastatina, onde foi reduzida sua atividade.

Arganosa e Marriot (1989) demonstraram que os ácidos orgânicos alteram as propriedades estruturais do colágeno. Além disso, a adição de ácido na carne diminui o $\mathrm{PH}$ além do ponto isoelétrico das proteínas e há aumento da capacidade de retenção de água, desse modo a estrutura muscular pode ser deformada pela umidade adquirida e tornar a carne mais macia (SEUSS; MARTIN, 1993).

A ocorrência de problemas de qualidade da carne, como carnes PSE (pálida, mole e exsudativa) ou DFD (escura, firme e seca) também afetam características sensoriais da carne como capacidade de reter água, cor e maciez da carne. Carne PSE apresenta PH abaixo no normal, por outro lado, carne DFD tem elevado $\mathrm{pH}$ final (LAWRIE, 1998; WEBB; CASEY, 2010; WAL et al., 1988). Ao analisar carne bovina Silva et. al. (1999) identificaram diminuição da força de cisalhamento em carnes DFD. Da mesma forma, Wal et. al. (1988) avaliaram as características sensórias de carne suína de diferentes $\mathrm{PH}(\mathrm{PH}<5,5$ = PSE; pH5,5-6,0 = normal; $\mathrm{pH}>$ 6,4=DFD) e observam que carne PSE apresenta maior força de cisalhamento e o oposto ocorre para DFD o que evidência o aumento de maciez da carne DFD.

\section{ESTIMULAÇÃO ELÉTRICA}

O método da estimulação elétrica surgiu como forma de evitar o encurtamento do músculo devido ao resfriamento rápido das carcaças. $\mathrm{O}$ encurtamento pelo frio ocorre quando o $\mathrm{pH}$ da carne é maior do que 6,0 com o ATP ainda disponíveis e a temperatura do músculo é inferior a $10^{\circ} \mathrm{C}$ (DEVINE et al., 2002; FRYLINCK et al., 
2009). O mecanismo da estimulação elétrica para evitar encurtamento do sarcômero é pela aceleração do processo de rigor, ou seja, maior glicólise e hidrólise de ATP, o que diminui o $\mathrm{PH}$ quando a carcaça ainda se mantém em altas temperaturas, provocando ruptura da membrana lisossômica e liberação proteinases que atuam na degradação de componentes miofibrilares, tornando o músculo macio antes do resfriamento das carcaças. As meias-carcaças estimuladas apresentaram maior queda de $\mathrm{PH}$ nas primeiras 3 horas do que meias-carcaças não-estimuladas (PUGA et al., 1999).

A estimulação de alta voltagem tem se mostrado mais efetiva no melhoramento da maciez da carne do que estimulação de baixa voltagem. Geralmente nos abatedouros a baixa voltagem é aplicada imediatamente após o abate, enquanto que a alta voltagem é aplicada de 20 a 60 minutos post mortem (HWANG; THOMPSON, 2001a). No entanto, trabalhos aplicando alta e baixa voltagem em tempos de 10 e 30 minutos post mortem demonstraram pequena a diferença de queda de $\mathrm{PH}$ da carne entre os dois sistemas de estimulação elétrica, sugerindo que o tipo de estimulação tem baixo impacto na maciez da carne (EIKELENBOOM et. al., 1985; SHAW et al., 1996).

Foi demonstrado por Hope-Jones et. al. (2010) que a estimulação elétrica de alta voltagem 30 minutos após o abate aumentou a maciez em decorrência da antecipação do rigor acionando as calpaínas e por diminuir a atividade da calpastatina.

Em um trabalho realizado com estimulação de alta e baixa voltagem, em tempos de três e 40 minutos pós abate, demonstrou que a estimulação elétrica 40 minutos post mortem, independentemente da voltagem, obteve carnes com menor força de cisalhamento e mais alto escore sensorial de maciez, enquanto que o tratamento de alta voltagem três minutos após o abate resultou em carne mais dura e comprimento de sarcômero menor quando comparado com os demais tratamentos, além de obter os níveis mais baixos de $\mu$ calpaína. Neste sentido, pode-se inferir que o rápido declínio de $\mathrm{PH}$, as altas temperaturas da carcaça, a redução precoce nos níveis de $\mu$ calpaína combinados com altos níveis de calpastatina ocorrido na estimulação aos três minutos aumenta o risco de encurtamento do sarcômero e consequentemente causa endurecimento da carne, tornando a estimulação elétrica ineficiente (HWANG; THOMPSON, 2001a). Resultados encontrados por Geesink et. al. (1994) também relatam que a redução precoce dos níveis de $\mu$ calpaína em conjunção com a obtenção precoce de rigor mortis e altas temperaturas tem um efeito adverso na maciez final da carne.

Carcaças estimuladas aos três minutos apresentaram aumento da calpastatina, o que coincidiu com o aumento na força de cisalhamento, comparado com a estimulação aos 40 minutos. $\mathrm{O}$ fato é explicado em virtude do efeito bloqueador da calpastatina sob a calpaína reduzindo a maciez da carne. No entanto, como esperado, todos os tratamentos resultaram em níveis de calpastatina significativamente menores do que no grupo controle sem estimulação (HWANG; THOMPSON, 2001a). O autor ainda relata que apesar da aplicação precoce do estímulo elétrico, tanto de alta quanto de baixa voltagem, ter efetividade reduzida, todos os tratamentos elétricos resultaram em maciez da carne significativamente maiores do que nos controles que não foram estimulados, contudo, para maximizar os efeitos da estimulação elétrica sobre a maciez da carne, deve- se evitar a aplicação de excessivos estímulos elétricos imediatamente após o abate. Esses resultados concordam com estudos anteriores, nos quais a ativação precoce do sistema de calpaínas pela estimulação elétrica foi um determinante significativo para a maciez da carne.

\section{TENDERIZAÇÃO}

A tenderização mecânica através de lâminas ou agulhas tem sido empregada na indústria da carne devido ao crescente interesse em processos rápidos que produzam efeitos uniformes na maciez da carne. Assim, a carne normalmente imprópria para o bife pode ser utilizada, sem amaciamento enzimático, obtendo efeito mais uniforme e mais fácil de controlar do que o método enzimático (HAYWARD et. al., 1980). Neste processo há a ruptura da estrutura muscular pela penetração de lâminas finas ou agulhas que perfuram a carne, consequentemente, há um aumento da maciez devido à destruição parcial do tecido conectivo e/ ou rompimento das fibras musculares (BENITO-DELGADO et. al., 1994).

O estudo conduzido por Puga et. al. (1999) avaliou os efeitos da tenderização mecânica, injeção de ácido acético $0,1 \mathrm{M}$, ácido lático $0,2 \mathrm{M}$, maturação por nove e 14 dias, e estimulação elétrica na maciez da carne, realizando uma comparação entre os métodos. A maturação por 14 dias apresentou $21 \%$ de aumento na maciez subjetiva e $12 \%$ de diminuição da força de cisalhamento; estes valores são semelhantes aos da estimulação elétrica. Já, a injeção com ácidos e a maturação por nove 
dias não apresentaram efeito significativo sobre a textura da carne tratada. A tenderização mecânica causou o maior efeito na maciez subjetiva, mas não apresentou a mesma melhora na diminuição da força de cisalhamento.

\section{SUSPENSÃO DAS CARCAÇAS}

É importante ter clareza que a textura da carne não varia apenas entre carcaças, mas também, entre músculo e ainda no próprio músculo (PLANT et. al., 1997).

Pesquisas também descobriram diferenças no comprimento de sarcômero de diversos músculos, sendo que os mais longos foram associados com menores valores de força se cisalhamento. Posicionamentos pré-rigor que aumentem o alongamento dos sarcômeros pode levar a maior maciez da carne (HERRING et al., 1967; RHEE et al., 2004). Carcaças suspensas através forame obturador resultaram em carnes mais macias, devido ao alongamento dos sarcômeros nos músculos longissimus dorsi, semimembranosus, semitendinosus, biceps femoris e gluteus medius (HOSTETLER et al., 1972). No trabalho de Grayson e Lawrence (2013) foi analisado se posicionamentos distintos do membro anterior interferem no comprimento de sarcômero e na força de cisalhamento para os músculos infraespinhoso, peitoral profundo, serrátio ventral, supraespinhoso, redondo maior e tríceps braquial. Todos os músculos, exceto o supraespinhoso, apresentaram o comprimento de sarcômero alterado de acordo com as diferentes formas de suspensão. A posição cranial resultou no alongamento do sarcômero para os músculos serrátio ventral e tríceps braquial, enquanto que a posição natural teve comprimento de sarcômero maior para os músculos peitoral profundo e redondo maior. O serrátio ventral na posição cranial teve menor força de cisalhamento do que a posição caudal, enquanto que o tríceps braquial da posição natural apresentou menor cisalhamento do que a posição paralela ou caudal e o comprimento de sarcômero foram correlacionados com a força de cisalhamento.

\section{CONCLUSÕES}

A maciez da carne é amplamente pesquisada pela importância que a característica organoléptica apresenta para o consumidor. Fatores relacionados ao post mortem são considerados os mais relevantes na maciez final de produto, sendo que a maturação enzimática e estimulação elétrica e estão entre os principais mecanismos envolvidos na maciez da carne que são ferramentas utilizadas pela indústria frigorífica.

\section{REFERÊNCIAS}

ANDRADE, P. L. et. al. Qualidade da carne maturada de bovinos Red Norte e Nelore. Revista Brasileira de Zootecnia, v. 39, n. 8, p. 1791-1800, 2010.

ALVES, D. D. et al. Maciez da Carne Bovina. Ciência Animal Brasileira, v. 6, n. 3, p. 135-149, 2005.

ARGANOSA, G. C.; MARRIOT, N. G. Organic acids as tenderizers of collagen in restructured beef. Journal of Food Science, v. 54, n. 5, p. 1173-1176, 1989.

ASGHAR, A.; YEATES, N. T. M. The mechanism for the promotion of tenderness in meat during the post-mortem process: a review. Critical Reviews in Food Science Nutrition, v. 10, n. 2, p. 115-145, 1978.

BEHRENDS, J. M. et al. Beef customer satisfaction: USDA quality grade and marination effects on consumer evaluations of top round steaks. Journal of Animal Science, v. 83, n. 3, p. 662-670, 2005.

BENITO-DELGADO, J. et al. Chuck Longissimus and Infraspinatus muscle characteristics as affected by rigor state, blade tenderization and calcium chloride injection. Journal of Food Science, v. 59, n. 2, p. 295-299, 1994.

DEVINE, C. E.; PAYNE, S. R.; WELLS, R. W. Effect of muscle restraint on sheep meat tenderness with rigor mortis at $18^{\circ} \mathrm{C}$. Meat Science, v. 60 , p. 155-159, 2002.

DRANSFIELD, E. Modelling post - mortem tenderisation - III: Role of calpain I in conditioning. Meat Science, v. 31, p. $85-94,1992$.

EIKELENBOOM, G.; SMULDERS, F. J. M.; RUDERUS, H.The effect of high and low voltage electrical simulation on beef quality.Meat Science, v.15, p. 247-254, 1985.

FAO. Food and Agriculture Organization of the United Nations. Food and agricultural commodities 
production in 2011. 2012. Disponível em: <http:// faostat.fao.org/site/339/default.aspx>. Acesso em: 04 abr. 2013.

FRYLINCK, L. et al. Evaluation of biochemical parameters and genetic markers for association with meat tenderness in South African feedlot cattle. Meat Science, v. 83, p. 657-665, 2009.

GEESINK, G. H. et al. Does electrical stimulation affect the speed of ageing or a ageing response? Sciences des Aliments, v. 14, p. 409 - 422, 1994.

GEESINK, G. H.; BEKHIT, A. D.; BICKERSTAFFEL, R. Rigor temperature and meat quality characteristics of lamb longissimus muscle. Journal Animal Science, v. 78, p. 2842-2848, 2000.

GEESINK, G. H. et al. Calpain is essential for postmortem proteolysis of muscle proteins. Journal Animal Science, v. 84, p. 2834-2840, 2006.

GRAYSON, A. L; LAWRENCE, T.E. Alternative pre-rigor fore shank positioning can improve beef shoulder muscle tenderness. Meat Science, v. 95, p. 36-41, 2013.

GODIKSEN, H. et al. Contribution of cathepsins $\mathrm{B}, \mathrm{L}$ and $\mathrm{D}$ to muscle protein profiles correlated with texture in rainbow trout (Oncorhynchusmykiss). Food Chemistry, v. 113, n.4, p. 889-911, 2009.

HAYWARD, L. H.; HUNT, M. C.; KASTNER, C. L. Blade tenderization effects on beef longissimus sensory and in stron textural measurements. Journal of Food Science, v. 45, n. 4, p. 925-930, 935, 1980.

HERRING, H. K. et al. Tenderness and associated characteristics of stretched and contracted bovine muscles. Journal of Food Science, v. 32, p. 317-323, 1967.

HOPKINS, D. L. et al. Explaining the variation in the shear force of lamb meat using sarcomere length, the rate of rigor onset and ph. Meat Science. Disponível em: <http://dx.doi.org/10.1016/j. meatsci.2011.03.004>. 2011. Acesso em: 28 mai. 2013.

HOSTETLER, R. L. et al. Effect of carcass suspension on sarcomere length and shear force of some major bovine muscles. Journal of Food Science, v. 37, p. 132-135, 1972.
HOPE-JONES, M. et al.The efficiency of electrical stimulation to counteract the negative effects of $\beta$-agonists on meat tenderness of feedlot cattle.Meat Science, v. 86 p. 699-705, 2010.

HUFF-LONERGAN, E.; ZHANG, W.; LONERGAN, S. M. Biochemistry of postmortem muscle-Lessons on mechanisms of meat tenderization.Meat Science, v. 86, n. 1, p. 184-195, 2010.

HWANG, I. H.; THOMPSON, J. M.The effect of time and type of electrical stimulation on the calpain sytem and meat tenderness in beef longissimus dorsi muscle. Meat science, v. 58, p. 135-144, 2001a.

HWANG, I. H.; THOMPSON, J. M. The interaction between $\mathrm{pH}$ and temperature decline early post mortem on the calpain system and objective tenderness in electrically stimulated beef Longissimus dorsi muscle. Meat Science, v. 58, p. 167 - 174, 2001 b.

JOOA, S.T. et al. Control of fresh meat quality through manipulation of muscle fiber characteristics. Meat Science, Apr., 2013.

KOOHMARAIE, M. Effect of $\mathrm{pH}$, temperature, and inhibitor on autolysis and catalytic activity of bovine skeletal muscle m -calpain. Journal of Animal Science, v. 70, n. 10, p. 3071-3080, 1992.

KOOHMARAIE, M; GEESINK, G. H. Contribution of postmortem muscle biochemistry to the delivery of consistent meat quality with particular focus on the calpain system. Meat Science, v. 74, p. 34-43, 2006.

LAWRIE, R. A. Ciencia de la carne. Zaragoza: Acribia, 1998. 380p.

MOMBACH, J. et al. Proposta de um modelo de gestão pela qualidade para um abatedouro/frigorífico de suínos. Revista Agrarian, v. 3, n. 10, p. 293300, 2010.

PIKE, M. M. et al. Quadratic relationship between early post-mortem glycolytic rate and beef tenderness.Meat science, v. 34, p. 13-26, 1993.

PLANT, T. M.; TAYLOR, D. G.; DHANDA, J.

$\mathrm{S}$. Tenderness relationships between four raw and cooked beef muscles. In: INTERNATIONAL CONGRESS OF MEAT SCIENCE TECHNOLOGY, 43, Ockland, 1997. Proceedings. Ockland: New Zealand Pastoral Agriculture Reserch Institute, 1997. p.784. 
PUGA, D. M. U. CONTRERAS, C. J. C.; TURNBULL, M. R. Avaliação do amaciamento de carne bovina de dianteiro (Tricepsbrachii) pelos métodos de maturação, estimulação elétrica, injeção de ácidos e tenderização mecânica. Ciência e Tecnologia de Alimentos, v.19, n.1, 1999.

RHEE, M. S. et al. Variation in palatability and biochemical traits within and among eleven beef muscles. Journal of Animal Science, v. 82, p. 534$550,2004$.

SANTOS, H. C.; BRANDELLI, A.; AYUB, M. A. $Z$. Influence of post-mortem aging in tenderness of chicken breast fillets. Ciência Rural, v.34, n.3, p. 905910, 2004

SAVELL, J. W.; MUELLER, S. L.; BAIRD, B. E.The chilling of carcasses.Meat Science, v. 70, p. 449-459, 2005.

SEUSS, I.; MARTIN, M. The influence of marinading with food acids on the composition and sensory properties of beef. Fleischwirtschaft, v. 73, n. 3, p. 292-295, 1993.

SHAW, F. D.; EUSTACE, I. J.; WARNER, R. D. Electrical stimulation of lamb carcass. In: Proceedings 42nd International Congress of Meat Science and Technology (p.410-411), 1996. Norway: Li1lehammer.

SILVA, J. A.; PATARATA, L.; MARTINS C. Infuence of ultimate $\mathrm{pH}$ on bovine meat tenderness during ageing. Meat Science, v. 52, p. 453-459, 1999.

SILVA SOBRINHO, A. G. et al. Características de qualidade da carne de ovinos de diferentes genótipos e idades ao abate. Revista Brasileira de Zootecnia, v. 34, p.1070 -1078, 2005.

TORNBERG, E. Biophysical aspects of meat tenderness. Meat Science, v. 43, p. 175- 191, 1996.

WAL, P. G.; BOLINK, A. H.; MERKUS G. S. M. Differences in Quality Characteristics of Normal, PSE and DFD Pork.Meat Science, v.24, p. 79-84, 1988.

WEBB, E.C.; CASEY, N. H. Physiological limits to growth and the related effects on meat quality, Livestock Science, v.130, p. 33-40, 2010.

ZEOLA N. M. B. L. et al. Cor, capacidade de reten- ção de água e maciez da carne de cordeiro maturada e injetada com cloreto de cálcio. Arquivo Brasileiro de Medicina Veterinária e Zootecnia, v.59, n.4, p.1058-1066, 2007. 